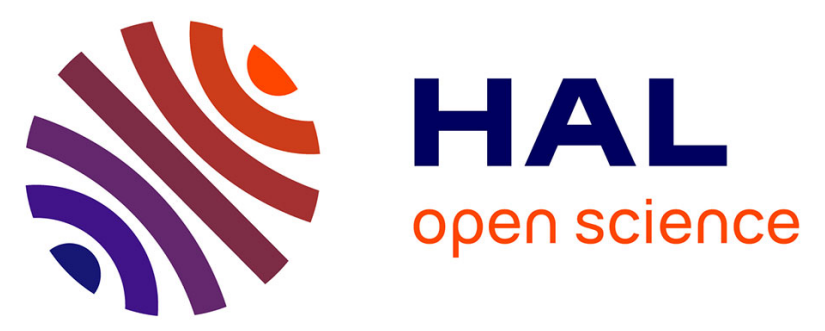

\title{
A cohesive zone model for the characterization of adhesion between cement paste and aggregates
}

Etienne Malachanne, Mouad Jebli, Frédéric Jamin, Eric Garcia-Diaz, Moulay Saïd El Youssoufi

\section{- To cite this version:}

Etienne Malachanne, Mouad Jebli, Frédéric Jamin, Eric Garcia-Diaz, Moulay Saïd El Youssoufi. A cohesive zone model for the characterization of adhesion between cement paste and aggregates. Construction and Building Materials, 2018, 193, pp.64 - 71. 10.1016/j.conbuildmat.2018.10.188 . hal01912699

\section{HAL Id: hal-01912699 \\ https://hal.science/hal-01912699}

Submitted on 5 Nov 2018

HAL is a multi-disciplinary open access archive for the deposit and dissemination of scientific research documents, whether they are published or not. The documents may come from teaching and research institutions in France or abroad, or from public or private research centers.
L'archive ouverte pluridisciplinaire HAL, est destinée au dépôt et à la diffusion de documents scientifiques de niveau recherche, publiés ou non, émanant des établissements d'enseignement et de recherche français ou étrangers, des laboratoires publics ou privés. 


\title{
A COHESIVE ZONE MODEL FOR THE CHARACTERIZATION OF ADHESION BETWEEN CEMENT PASTE AND AGGREGATES
}

\author{
Etienne Malachanne ${ }^{\mathrm{a}, *}$, Mouad Jebli ${ }^{\mathrm{a}, \mathrm{b}}$, Frederic Jamin ${ }^{\mathrm{b}, \mathrm{c}}$, Eric \\ Garcia-Diaz $^{\mathrm{a}}$, Moulay-Said El Youssoufi ${ }^{\mathrm{b}, \mathrm{c}}$ \\ ${ }^{a}$ C2MA, IMT Mines Ales, Univ. Montpellier, Ales, France \\ ${ }^{b}$ LMGC, Univ. Montpellier, CNRS, Montpellier, France \\ ${ }^{c}$ MIST Lab., IRSN, CNRS, Univ. Montpellier, France
}

\begin{abstract}
The influence of an Interfacial Transition Zone on mechanical behavior of concrete has been established by many authors. Several experimental studies have highlighted the weak mechanical properties of Interfacial Transition Zone due mainly to higher porosity than other phases, or to the presence of initial damage at the interface between paste and aggregates. Thus, it is necessary to take this zone into account when modelling the mechanical behavior of concrete, particularly outside of the elastic domain. Various analytical or numerical methods have been proposed, and some of these replace the physical representation of an Interfacial Transition Zone, by an imperfect interface between paste and aggregates, and an adhesion model with specific mechanical properties. In this work a cohesive zone model coupling adhesion, friction and unilateral contact is applied to a finite element model of a cement paste-aggregate composite, designed to test interface mechanical properties.
\end{abstract}

\footnotetext{
*Corresponding author

Email address: etienne.malachanne@mines-ales.fr (Etienne Malachanne)
} 
Cohesive zone model parameters are calibrated using an experimental study of the same composite, submitted to mechanical loading during hydration and leaching of cement paste. This numerical approach allows modelling of the mechanical behavior of a composite until the tensile strength is reached. Moreover evolution of cohesive zone model parameters during hydration and leaching, shows a partial adhesion on contact surfaces between cement paste and aggregate. This could explain initial interface damage.

Keywords:

Concrete, Numerical model, Aggregate-cement paste interface, Cohesive Zone Model, Finite Elements Model, Mechanical behavior

\section{INTRODUCTION}

Modelling of concrete behavior requires an understanding of mechanical properties of each phase and interphase. Many authors have investigated the role of interfacial transition zones (ITZ) in concrete behavior $[1,2]$. In several studies, the question of a higher porosity [3], or porosity gradient [4] in this zone has been adressed. Other work has observed an influence of the aggregates microstructure on these interfaces [5]. Indeed the roughness of aggregates may influence their adhesion to the matrix [6], and the porosity of aggregates could reduce their depth as in lightweight concrete [7]. Thus, the zone between cement paste and aggregates - or mortar and aggregates - presents different microstructural and mechanical properties than the two other phases, which are not always clearly defined. Nevertheless, specific mechanical properties around aggregates must be taken into account if the mechanical behavior of mortar or concrete is to be modelled [8]. Different 
ways are proposed for that. Many studies consider ITZ as a genuine third phase, through a finite element model $[9,4]$. A third material with higher porosity is modelled [10]. This method physically represents the interphase, carrying some difficulties for meshing, due to thinness of ITZ (only a few $\mu m$ thick). To overcome this difficulty, certain authors proposed a micromechanical analytical model that takes into account a third zone between the lightweight aggregates and mortar with different apparent material properties $[11,12]$. If the mechanical specificity of the interface is considered in analytical studies, any structural effects are taken into account. In the same way, some analytical research has used classical methods of homogenization, considering concrete as a three-phase heterogeneous composite [13]. These methods determine homogeneous elastic moduli quite accurately, but are limited in their prediction of concrete strength behavior. Few mechanical models take into account the imperfect contact between ITZ and the aggregate surface. One way to approach this aspect of the problem is to introduce mechanical damage induced by the quality of the matrix-aggregate interface [14]. Alternatively an accurate representation of aggregates by a finite element mesh can be used, having replaced ITZ by a damage at the interface paste-aggregate interface [15].

Another way to take into account the imperfect contact is to use an adhesion model. In such a model, mathematical adhesive laws are introduced at the interface, instead of a physical representation [16]. Some models have been used to simulate fiber debonding on composite materials [17] or as homogenization methods [18]. Adhesion models are used in many physical domains such as Civil Engineering for masonry [19, 20], or fiber-reinforced 
concrete [21]. Some Cohesive Zone Models (CZM) could be used between finite elements $[22,23,24,25]$ or with discrete elements [26], and these introduce friction adhesion and unilateral contact laws [27, 28, 29]. These last models will be used in the numerical investigation presented in this paper, where an imperfect contact area is introduced in a composite of two limestone aggregates linked by a cement paste. In previous reports [30, 31, 32], similar composites were described. These were designed to submit cement paste-aggregate interfaces to several mechanical tests, particularly tensile and shear tests. Here, a numerical study based on the experimental response of the interface is proposed. The aim of our work is to calibrate parameters of cohesive law, and characterize mechanical and geometrical properties of interfaces through these parameters during hydration of cement paste, and after its degradation by leaching.

\section{MATERIALS AND METHODS}

\subsection{Experimental results}

All the experimental methods and results used in this paper to calibrate the numerical model, are described in the Ph.D of Mouad Jebli from the University of Montpellier [33]. Presuming that concrete presented weak mechanical properties at the interphase, a composite was designed with two cubic limestone aggregates linked by a layer of cement paste especially to load cement paste-aggregate interface. The composite is represented in Figure 1a. Several mechanical tests were carried out at different ages of curing of the cement paste [32] and after its degradation by an accelerated leaching mechanism [31]. If Young's modulus of limestone aggregates was known, 
and is equal to $60 \mathrm{GPa}$, compressive tests were carried out on cement paste, during hydration and degradation by leaching, to obtain elastic properties. These parameters are recapituled in Table 1 for hydration, and Table 2 for leaching.

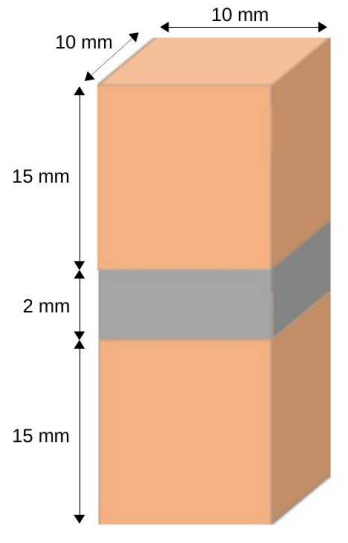

(a) Sample of two limestone aggregates $(10 \times 15 \times 10 \mathrm{~mm})$ linked by a cement paste $(10 \times$ $2 \times 10 \mathrm{~mm})$

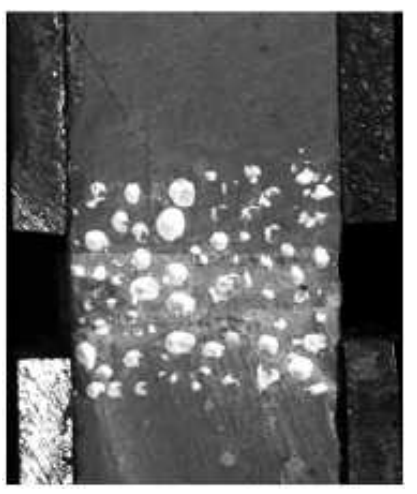

(b) Speckle pattern on composite sample for image correlation

Figure 1: Composite sample used in experimental studies [31, 32]

A tensile load was applied to the composite, at a velocity of $0.01 \mathrm{~mm} / \mathrm{s}$ until rupture. The onset of rupture and cracking of the sample were recorded using a high-speed digital camera, and displacements were measured by image correlation method as shown in Figure 1b. All mechanical tests were carried out on three samples and stress-strain curves obtained for one composite during hydration and leaching are shown in Figure 2.

Degradation of cement paste, could be visualized as a leached section using a phenolphthalein test, as shown in Figure 3. It appears that the safe 


\begin{tabular}{cc}
\hline Hydration time (days) & Young's modulus (GPa) \\
\hline 2 & 6.3 \\
7 & 9.3 \\
15 & 12.4 \\
28 & 12.4 \\
90 & 12.5 \\
\hline
\end{tabular}

Table 1: Young's modulus of cement paste for several hydration times

\begin{tabular}{cc} 
Degradation time (hours) & Young's modulus (GPa) \\
\hline 1 & 9.3 \\
6 & 7.7 \\
24 & 6.0 \\
48 & 5.5
\end{tabular}

Table 2: Evolution of Young's modulus of cement paste during degradation

surface, colored in pink, decreases during leaching. The method used to accelerate leaching of the cement paste with ammonium nitrate solution, had been developed in previous work, on composites made with spherical inclusions [30]. This method was then applied to the parallelepipedic composite used here [31].

Next we defined the degraded surface $S_{d}$. The schematic section represented in Figure 4 shows a degraded thickness called $e_{p h}$.

Considering $L$ as the side of the section, the sound surface $S_{s}$ can be 


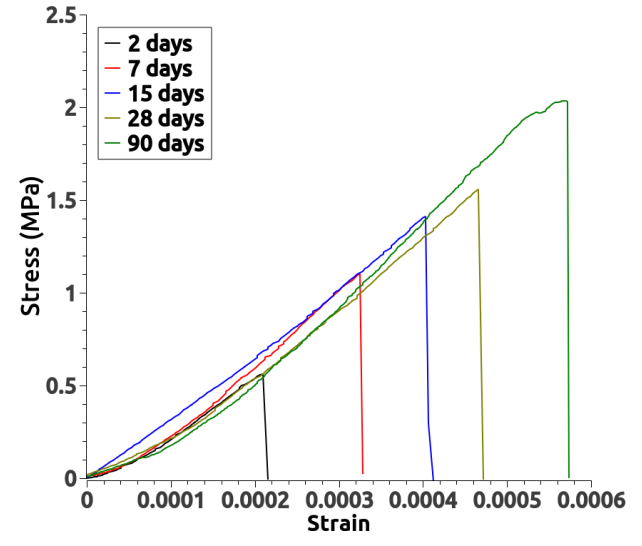

(a) Hydration

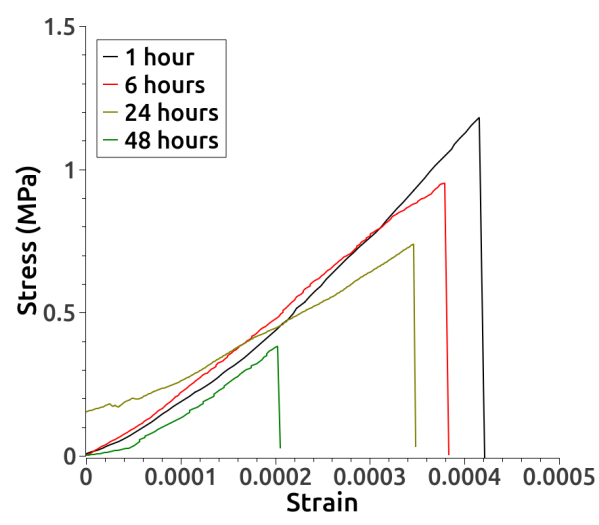

(b) Leaching

Figure 2: Results of tensile tests at increasing hydration and leaching times

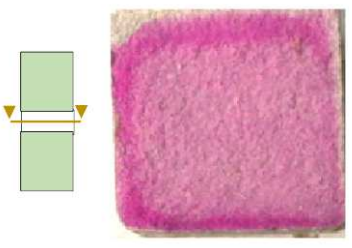

sound sample

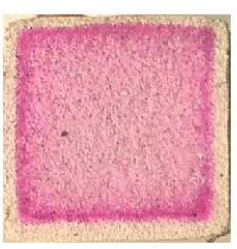

$6 h$ leaching time

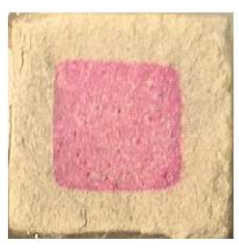

1 day leaching time

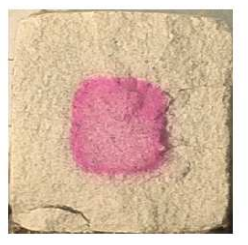

3 days leaching time

Figure 3: Degraded surface of cement paste revealed by phenolphthalein

defined as :

$$
S_{s}=\left(L-2 e_{p h}\right)^{2}
$$

Thus calling $S_{0}$ the initial section, the degraded section $S_{d}$ leads to :

$$
S_{d}=S_{0}-S_{s}
$$

The measurement of the degraded surface $S_{d}$ allows a degradation rate to be defined :

$$
\delta_{d}=\frac{S_{d}}{S_{0}}
$$




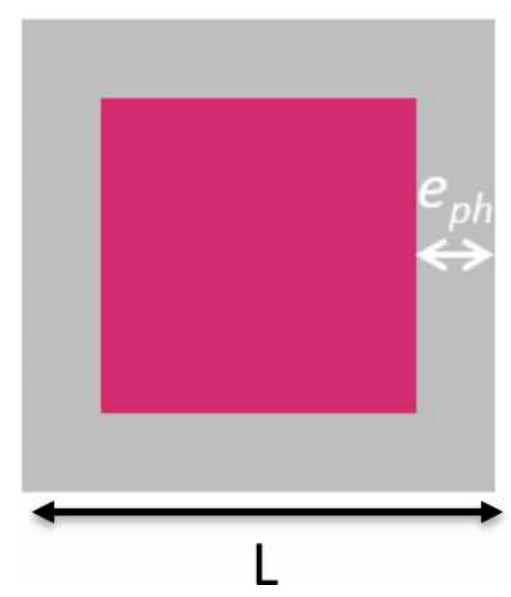

Figure 4: Degraded thickness $e_{p h}$

A match between leaching times and the degradation rate is summarized in Table 3. Considering following degradation of the composite or cement paste allows expression according to the degradation rate.

\begin{tabular}{cc}
\hline Leaching time (hours) & Degradation rate \\
\hline 1 & 0.20 \\
6 & 0.40 \\
24 & 0.70 \\
48 & 0.84 \\
\hline
\end{tabular}

Table 3: Leaching times vs degradation rate

All the results coming from the experimental methods briefly presented in this section, will now be used to set CZM parameters. 


\subsection{Numerical model}

\subsubsection{Cohesive zone model}

To characterize the interface parameter, a finite element model of the composite sample, with a cohesive zone model at the interface between cement paste and aggregates was developed. We first briefly recall the CZM chosen. Only the main constitutive equations that introduce parameters needed to set the model are presented in this paper. A complete description of the CZM is detailed in [27]. This model considers a non-penetration situation between two bodies in contact, here cement paste and aggregates. These two materials are meshed by finite elements. The unilateral contact is coupled with friction, coming from the Coulomb law between the two materials, and an adhesion intensity governed by a state variable which describes the contact state. This $\beta$ variable, introduced by Fremond [34], provides the adhesion intensity between the two bodies in contact. It is defined by a classical damage parameter $D$ included between 0 (no damage) and 1 (rupture) such that :

$$
\beta=1-D
$$

Thus, adhesion linked to damage between the aggregates and cement paste is :

- $\beta=1$ total adhesion

- $0<\beta<1$ partial adhesion

- $\beta=0$ no adhesion 
The thermodynamic description, based on the standard material generalized theory [35], needs the definition of state variables associated with thermodynamic forces. Thus, we can consider the reversible forces $R_{N}$ and $R_{T}$ associated with the interface relative jump displacements $\left[u_{N}\right]$ and $\left[u_{T}\right]$. $N$ and $T$ indices indicate decomposition into normal and tangential parts on the contact surface. Thus, $R_{N}$ and $R_{T}$ are considered as normal and tangential contact forces :

$$
\vec{R}=R_{N} \vec{n}+\overrightarrow{R_{T}} \text { with } R_{N}=\vec{R} \cdot \vec{n}
$$

In the same way, the displacement is decomposed as follows :

$$
[u]=\left[u_{N}\right] n+\left[u_{T}\right] \text { with }\left[u_{N}\right]=[u] . n
$$

In this problem the state variables are $\beta,\left[u_{N}\right]$ and $\left[u_{T}\right]$, and we introduce a free energy potential :

$$
\psi\left(\left[u_{N}\right],\left[u_{T}\right], \beta\right)=\frac{C_{N}}{2}\left[u_{N}\right]^{2} \beta^{2}+\frac{C_{T}}{2}\left[u_{T}\right]^{2} \beta^{2}-w h(\beta)
$$

with $C_{N}$ and $C_{T}$ being the normalized normal and tangential interface stiffness (expressed in $\mathrm{Pa} / \mathrm{m}$ ), and $w h(\beta)$ a general form of the interface decohesion energy. We chose $h(\beta)=\beta$ to recognize $w$ as Dupre's energy, considered as the interface adhesion energy.

As explained in the work of Raous et al., [27], the main constitutive laws of contact at the interface come from sub-differentiation of the free energy potential, and a dissipation potential, with respect to the state variables 
$\left[u_{N}\right],\left[u_{T}\right]$ and $\beta$. As a consequence we can define the unilateral contact with adhesion :

$$
\begin{aligned}
R_{N}-C_{N}\left[u_{N}\right] \beta^{2} & \geq 0 \\
{\left[u_{N}\right] } & \geq 0 \\
\left(R_{N}-C_{N}\left[u_{N}\right] \beta^{2}\right)\left[u_{N}\right] & =0
\end{aligned}
$$

where the first equation ensures contact between two bodies, the second non-penetration between two bodies, and the third the impossibility of having both contact force and displacement.

Friction with adhesion is defined as the Coulomb friction law, with a damage parameter $\beta$ at the interface :

$$
\begin{aligned}
|| R_{T}-C_{T}\left[u_{T}\right] \beta^{2} \| & \leq \mu\left|R_{N}-C_{N}\left[u_{N}\right] \beta^{2}\right| \\
|| R_{T}-C_{T}\left[u_{T}\right] \beta^{2} \| & <\mu\left|R_{N}-C_{N}\left[u_{N}\right] \beta^{2}\right| \Rightarrow\left[\dot{u_{T}}\right]=0 \\
|| R_{T}-C_{T}\left[u_{T}\right] \beta^{2} \| & =\mu\left|R_{N}-C_{N}\left[u_{N}\right] \beta^{2}\right| \Rightarrow \exists \lambda>0,\left[\dot{u_{T}}\right]=\lambda\left(R_{T}-C_{T}\left[u_{T}\right] \beta^{2}\right)
\end{aligned}
$$

where $\mu$ is a friction coefficient.

Time evolution of $\beta$ variable is governed by the dissipation potential is defined by the following relationship :

$$
\dot{\beta}=-\frac{1}{b}\left(\omega-\beta\left(C_{N}\left[u_{N}\right]^{2}+C_{T}\left[u_{T}\right]^{2}\right)\right)
$$

where $b$ is the viscosity of the interface. We presume that the interface between cement paste and aggregates is without viscosity, $\beta$ is considered equal to 1 at the begining and fall to 0 when the contact is broken. 
Finally, the shape of the cohesive law is shown by the curve of Figure 5 which demonstrates a normal reaction with respect to the normal displacement jump. The force-peak represents the adhesion limit. Applying this to the composite presented previously, we consider that damage only occurs at the interface, and we presume that the energy of adhesion is equal to the area under the curve.

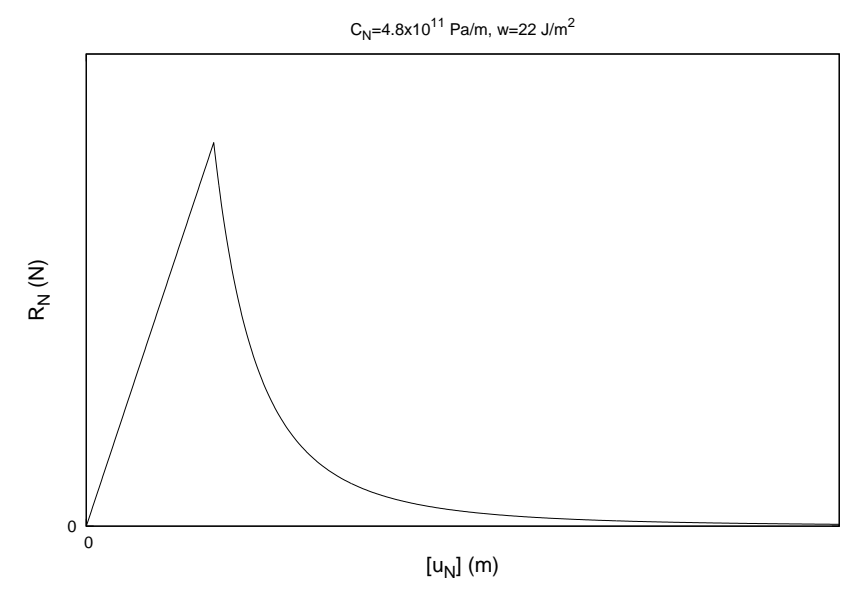

Figure 5: Shape of the cohesive law

\subsubsection{Finite element model}

A three-dimensional finite element model of the composite was determined and geometry was meshed with $\mathrm{H} 8$ tetrahedron elements, as shown in Figure 6. The numerical calculation was performed with the LMGC90 software [36] developed at the University of Montpellier. This software was developed for contact dynamic methods. Here, if a quasi-static method could have been chosen, the displacement velocity at the interface, which is potentially high, would have led us to use the theta-method time integration with 
$\theta=0.55$, and a constant time step of $1 \times 10^{-4} \mathrm{~s}$. Symmetry boundary conditions were used, and as in the experimental study a tensile load was imposed with a velocity $v_{y}=0.01 \mathrm{~mm} / \mathrm{s}$ applied to the upper face. The numerical sample generated is compounded by two elastic phases, aggregates and cement paste. The decohesion between them is driven by the CZM law, and is represented in the finite element model by "contactors" at the interface. These contactors are placed on nodes and detection is realized at each time step. Rupture occurs when contact is lost between the two bodies $(\beta=0)$. A mesh sensitivity was analyzed and this did not have a significant influence on numerical results. Thus, a coarse meshing was chosen, to reduce the calculation time.

To calibrate cohesive law, we have to identify the stiffness $C_{N}$ and $C_{T}$, the decohesion energy $w$ and the friction coefficient $\mu$. Here a tensile test is considered so the displacement will only be normal, and as a consequence $u_{T}=0$. According to (7), only $C_{N}$ will be activated in this computation, and only the unilateral contact conditions are needed in this case. The term $w$ could be considered as a Dupre energy value [27]. As explained above, initially we presume that this comes from the area under experimental stressstrain curves. It could be calculated directly from Figure 2. For example, for 28 days of composite hydration, decohesion energy leads to :

$$
w=\sigma \times u=1.55 \times 10^{6} \times 1.5 \times 10^{-5}=23 \mathrm{~J} / \mathrm{m}^{2}
$$

Thus only $C_{N}$ must be calibrated, and for that $C_{N}$ is set to fit the numerical stress-strain curve to the experimental one. 


\section{RESULTS}

After numerical computation of tensile loading, decohesion between cement paste and aggregates appears as shown in Figure 6. This gives axial displacements.

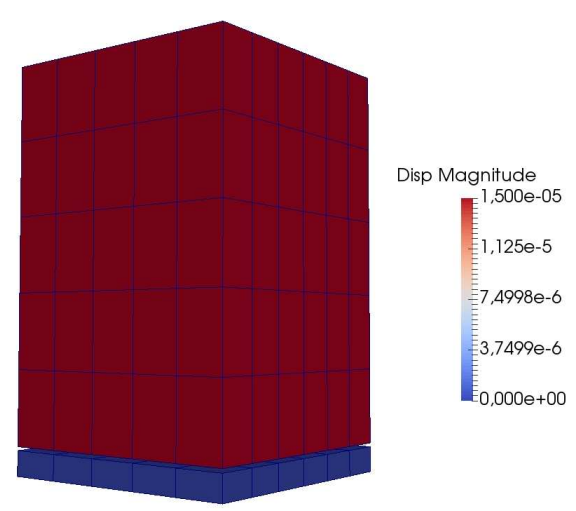

Figure 6: Vertical mechanical displacements with decohesion

As explained above, Figure 7 provides an example of the calibration of $C_{N}$ and $w$ after several numerical computations, for 28 days of composite age curing. The decohesion energy $w$ is slightly modified relative to the experimental value. Then these computations are confronted against 3 different experimental results for each hydration time or degradation rate.

First we present the evolution of the decohesion energy $w$. As explained above, the identified value is close to the experimental one. Slight calibration was effected to obtain the exact experimental tensile strength. As shown in Figure 8, the decohesion energy increases during hydration, particularly between 2 and 15 days. In contrast it decreases with leaching.

As the previously calibrated parameter, the interface stiffness $C_{N}$ was chosen to fit numerical stress-strain curves with to experimental ones. Once 


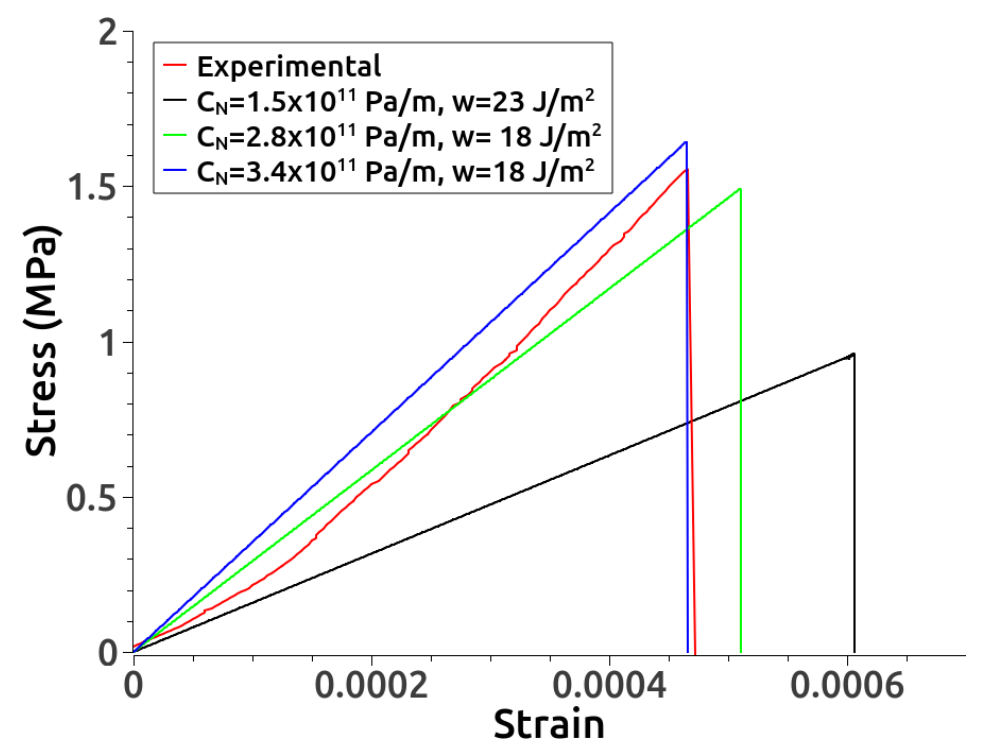

Figure 7: Setting $C_{N}$ and $w$ for a 28 day curing composite

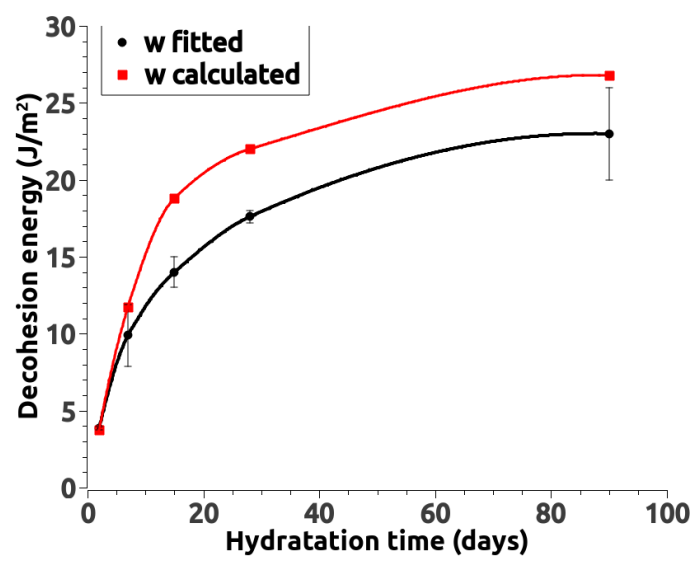

(a) Hydration

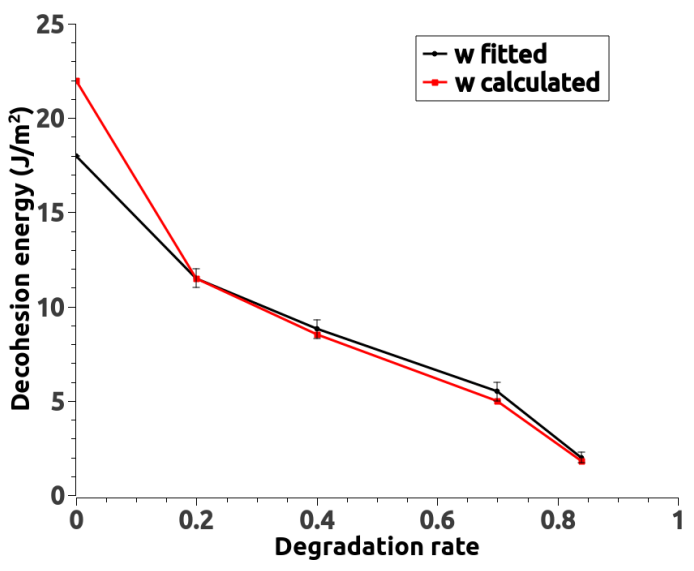

(b) Leaching

Figure 8: Numerical identification of decohesion energy

more, the evolution presented in Figure 9 shows an increase during hydration and a decrease during leaching. 


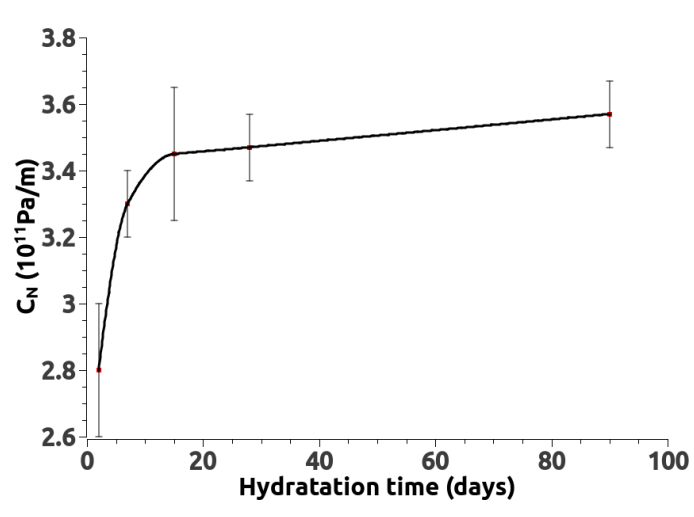

(a) Hydration

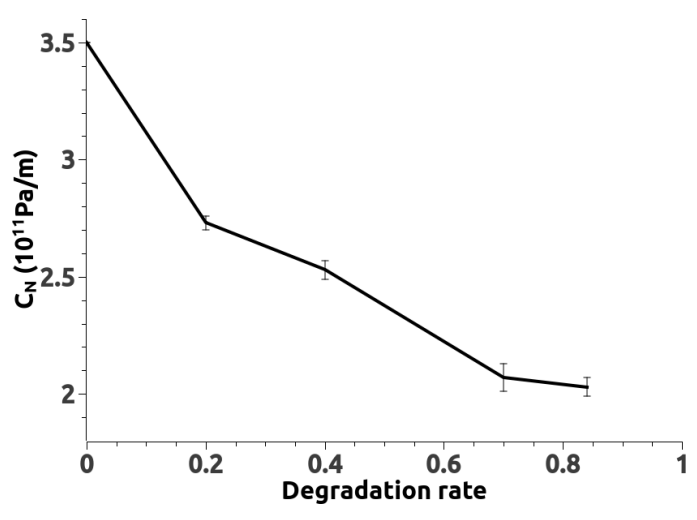

(b) Leaching

Figure 9: Numerical identification of normal stiffness at interface

These parameters will be used so that, in the next section, the mechanical behavior of the interface between cement paste and mortar can be characterized.

\section{DISCUSSION}

Numerical computation results presented in the previous section, have shown that the modelling method chosen using a cohesive zone model instead of a physical representation of ITZ, allows the mechanical response of the cement paste-aggregate composite until the rupture to be described. Indeed, when CZM parameters are set, a numerical model is able to supply Young's modulus and the composite tensile strength.

$C_{N}$ and $w$ parameters were calibrated using experimental Young's modulus calculated on the tensile stress-strain curves (Figure 2). For 28 day curing of the composite, the Young's modulus value is equal to $3.9 \mathrm{GPa}$ according 
to [32]. This value is lower than the cement paste one, but we can now calculate the homogeneous theoretical stiffness. For this kind of composite, geometrical characteristics allow the application of a serial paste-aggregate model as shown in Figure 10.

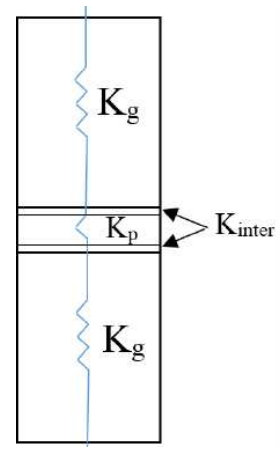

Figure 10: Representation of the composite as an assembly of serial stiffnesses

Considering the contact zone between paste and aggregates as a third phase, homogeneous serial stiffness of the composite $K_{c}$ is related to other stiffnesses through the following equation :

$$
\frac{1}{K_{c}}=\frac{2}{K_{g}}+\frac{2}{K_{\text {int }}}+\frac{1}{K_{p}}
$$

Where $K_{g}$ is the aggregate stiffness, $K_{\text {int }}$ the contact stiffness and $K_{p}$ the cement paste one. For continuous media, such as cement paste and aggregates discussed here, the parallelepipedic geometry of the composite sample allows the definition of a relationship between stiffness and the Young's modulus to their section $S_{0}$ and lengths:

$$
K_{p, g}=\frac{E_{p, g} \times S_{0}}{L_{p, g}}
$$


Thus, $K_{p}$ and $K_{g}$ are calculated from experimental Young's modulus values for aggregates and cement paste. Since the contact between cement paste and aggregates is considered as an imperfect mechanical link, we presume that the contact surface, $S_{\text {int }}$, is different from $S_{0}$. Thus the calculation of $K_{\text {int }}$ is impossible using equation (13). However the normal interface stiffness $C_{N}$, expressed in $[\mathrm{Pa}] /[\mathrm{m}]$, or in $[\mathrm{N}] /[\mathrm{m}]^{3}$, can be related to the stiffness $K_{\text {int }}$ expressed in $[\mathrm{N}] /[\mathrm{m}]$ by the relationship:

$$
K_{\text {int }}=C_{N} \times S_{\text {int }}
$$

Thus, the calculation of $S_{\text {int }}$ for each $C_{N}$, using equations (12) and (14) leads to:

$$
S_{\text {int }}=\frac{2}{C_{N}} \times \frac{K_{g} K_{c} K_{p}}{K_{g} K_{p}-2 K_{c} K_{p}-K_{c} K_{g}}
$$

where the composite stiffness $K_{c}$ is directly deduced from the experimental value of Young's modulus. These contact sections calculated for each stiffness provide the evolution of the adhesion between cement paste and aggregates during hydration and leaching. Figure 11 shows the evolution of the $\frac{S_{i n t}}{S_{0}}$ ratio. The ratio is smaller than 1 , being around 0.7 , which suggests that the whole of the available section would not be in contact at the interface. Moreover, the adhesive section seems to remain constant during hydration.

While these results are hardly visible in experimental studies, they could suggest two analyses of the interface adhesion mechanism. With only a partial adhesion of around $70 \%$ between the aggregates and cement paste, we can presume that the interface is imperfect. This initial failure could be linked to the higher porosity and initial damage at the interface, inducing weak me- 


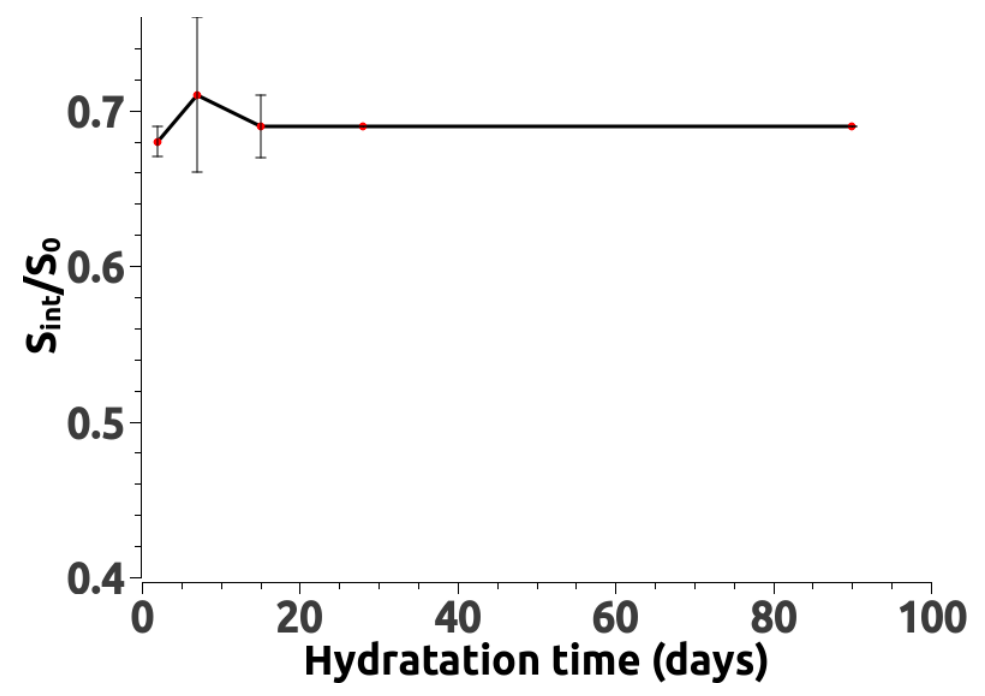

Figure 11: Evolution of ratio between composite section and adhesive section during hydration

chanical properties [7]. Moreover, we can imagine that a strong dependency exists between the adhesive section and interface quality. Unfortunately, no experimental investigations have allowed this phenomenon to be highlighted. Nevertheless we can propose that adhesion must be increased along with the interface roughness. A second piece of information provided by the ratio between the adhesive and composite sections, is stability during hydration. In contrast to stiffness or Young's modulus of interface and to the main mechanical properties of the composite, which increase during hydration, "glue dots" between the cement paste and aggregates seem to be fixed as soon as hydration starts, whereas their stiffness increases.

The evolution of this ratio during leaching shows another tendency, as presented in Figure 12. Indeed, according to the numerical evolution of interface stiffness, the adhesive section between cement paste and aggregates 


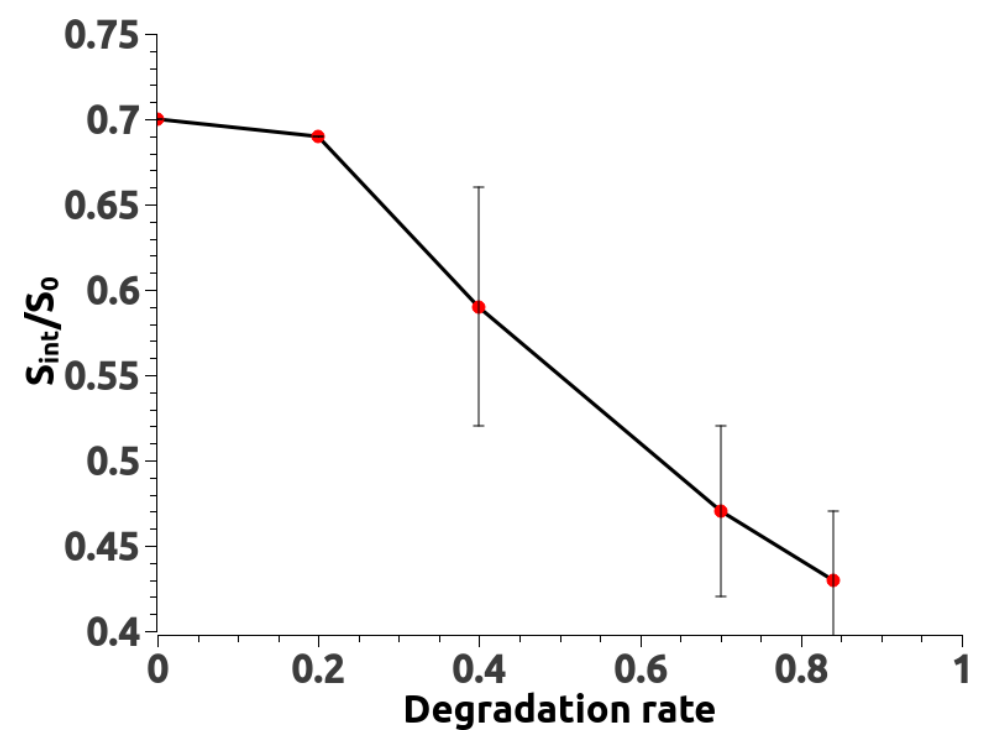

Figure 12: Evolution of ratio between composite section and adhesive section during leaching

decreases. After a critical value of the degradation rate around of 0.2 , the ratio falls to 0.4 for a degradation rate of approximately 0.84 . Considering that during hydration only $70 \%$ of the cement paste section is in contact with aggregates, the decrease of the $\frac{S_{i n t}}{S_{0}}$ ratio may indicate that "glue dots" are gradually destroyed by leaching, slowly ruining contacts and increasing damage at the interface, with consequences on mechanical behavior of the composite.

\section{CONCLUSION}

The work presented in this paper is based on an original experimental study, with a cement paste/aggregate composite designed to load specifically the interface between the two materials. The mechanical response to ten- 
sile tests was used to calibrate numerical modelling of the composite. In this finite element model, the composite is considered as a biphasic elastic material, linked by an imperfect interface where cohesive zones were introduced. Interface stiffness coming from the cohesive law chosen was fitted to the experimental results during hydration and degradation phenomena due to leaching. The calculation of the adhesive section between aggregates and cement paste, showed that during hydration only $70 \%$ of the available contact surface is used to induce probable initial damage at the interface. Moreover, a degradation rate of the adhesive section is held steady until $20 \%$, and then decreases with leaching.

\section{References}

[1] S. Diamond and J. Huang. The itz in concrete a different view based on image analysis and sem observations. Cement and Concrete Composites, 23(2-3):179-188, Apr 2001.

[2] J.P. Ollivier, J.C. Maso, and B. Bourdette. Interfacial transition zone in concrete. Advanced Cement Based Materials, 2(1):30-38, Jan 1995.

[3] S. Diamond. Considerations in image analysis as applied to investigations of the itz in concrete. Cement and Concrete Composites, 23(23):171-178, Apr 2001.

[4] F. Bernard and S. Kamali-Bernard. Numerical study of itz contribution on mechanical behavior and diffusivity of mortars. Computational Materials Science, 102:250-257, May 2015. 
[5] S. Erdem, A.R. Dawson, and N.H. Thom. Impact load-induced microstructural damage and micro-structure associated mechanical response of concrete made with different surface roughness and porosity aggregates. Cement and Concrete Research, 42(2):291-305, Feb 2012.

[6] S. Erdem, A.R. Dawson, and N.H. Thom. Influence of the micro- and nanoscale local mechanical properties of the interfacial transition zone on impact behavior of concrete made with different aggregates. Cement and Concrete Research, 42(2):447-458, Feb 2012.

[7] P. Vargas, O. Restrepo-Baena, and J. I. Tobn. Microstructural analysis of interfacial transition zone (itz) and its impact on the compressive strength of lightweight concretes. Construction and Building Materials, 137:381-389, Apr 2017.

[8] C.M. Neubauer, H.M. Jennings, and E.J. Garboczi. A three-phase model of the elastic and shrinkage properties of mortar. Advanced Cement Based Materials, 4(1):6-20, Jul 1996.

[9] L. Shuguang and L. Qingbin. Method of meshing itz structure in 3D meso-level finite element analysis for concrete. Finite Elements in Analysis and Design, 93:96-106, Jan 2015.

[10] F. Grondin and M. Matallah. How to consider the interfacial transition zones in the finite element modelling of concrete? Cement and Concrete Research, 58:67-75, Apr 2014.

[11] Y. Ke, S. Ortola, A.L. Beaucour, and H. Dumontet. Identification of microstructural characteristics in lightweight aggregate concretes by mi- 
cromechanical modelling including the interfacial transition zone (itz). Cement and Concrete Research, 40(11):1590-1600, Nov 2010.

[12] Y. Ke, S. Ortola, A.L. Beaucour, and H. Dumontet. Micro-stress analysis and identification of lightweight aggregates failure strength by micromechanical modeling. Mechanics of Materials, 68:176-192, Jan 2014.

[13] C. Zhou, K. Li, and F. Ma. Numerical and statistical analysis of elastic modulus of concrete as a three-phase heterogeneous composite. Computers \& Structures, 139:33-42, Jul 2014.

[14] D. Keinde, S. Kamali-Bernard, F. Bernard, and I. Cisse. Effect of the interfacial transition zone and the nature of the matrix-aggregate interface on the overall elastic and inelastic behavior of concrete under compression : a 3d numerical study. European Journal of Environmental and Civil Engineering, 18(10):1167-1176, 2014.

[15] A. Gangnant, J. Saliba, C. La Borderie, and S. Morel. Modeling of the quasibrittle fracture of concrete at meso-scale: Effect of classes of aggregates on global and local behavior. Cement and Concrete Research, 89:35-44, Nov 2016.

[16] Michel Raous. Interface models coupling adhesion and friction. Comptes Rendus Mcanique, 339(7):491 - 501, 2011. Surface mechanics : facts and numerical models.

[17] J.L. Chaboche, F. Feyel, and Y. Monerie. Interface debonding models: a viscous regularization with a limited rate dependency. International Journal of Solids and Structures, 38(18):3127 - 3160, 2001. 
[18] J C Michel and P Suquet. An analytical and numerical study of the overall behaviour of metal-matrix composites. Modelling and Simulation in Materials Science and Engineering, 2(3A):637, 1994.

[19] F. Fouchal, F. Lebon, and I. Titeux. Contribution to the modelling of interfaces in masonry construction. Construction and Building Materials, 23(6):2428-2441, Jun 2009.

[20] Giulio Alfano and Elio Sacco. Combining interface damage and friction in a cohesive-zone model. International Journal for Numerical Methods in Engineering, 68(5):542-582, 2006.

[21] R. H. J. Peerlings, R. de Borst, W. A. M. Brekelmans, and M. G. D. Geers. Gradient-enhanced damage modelling of concrete fracture. Mechanics of Cohesive-frictional Materials, 3(4):323-342, 1998.

[22] M. Elices, J. Planas, and G.V. Guinea. Fracture mechanics applied to concrete. European Structural Integrity Society, 26:183-210, 2000.

[23] M. Elices, G.V. Guinea, J. Gmez, and J. Planas. The cohesive zone model: advantages, limitations and challenges. Engineering Fracture Mechanics, 69(2):137-163, Jan 2002.

[24] F. Moroni and A. Pirondi. Cohesive zone model simulation of fatigue debonding along interfaces. Procedia Engineering, 10:1829-1834, 2011.

[25] J. Roesler, Glaucio H. Paulino, and C. Park, K.and Gaedicke. Concrete fracture prediction using bilinear softening. Cement and Concrete Composites, 29(4):300-312, Apr 2007. 
[26] R. de Borst, J.J.C. Remmers, and A. Needleman. Mesh-independent discrete numerical representations of cohesive-zone models. Engineering Fracture Mechanics, 73(2):160-177, Jan 2006.

[27] M. Raous, L. Cangemi, and M. Cocu. A consistent model coupling adhesion, friction, and unilateral contact. Computer Methods in Applied Mechanics and Engineering, 177(3-4):383-399, 1999.

[28] C. Talon and A. Curnier. A model of adhesion coupled to contact and friction. European Journal of Mechanics - A/Solids, 22(4):545-565, Aug 2003.

[29] Michel Fremond and Boumediene Nedjar. Damage, gradient of damage and principle of virtual power. International Journal of Solids and Structures, 33(8):1083 - 1103, 1996.

[30] M. Jebli, F. Jamin, E. Garcia-Diaz, M. El Omari, and M-S. El Youssoufi. Influence of leaching on the local mechanical properties of an aggregatecement paste composite. Cement and Concrete Composites, 73:241-250, Oct 2016 .

[31] M. Jebli, F. Jamin, C. Pelissou, E. Malachanne, E. Garcia-Diaz, and M-S. El Youssoufi. Leaching effect on mechanical properties of cementaggregate interface. Cement \& Concrete Composites, 87:10-19, 2018.

[32] M. Jebli, F. Jamin, E. Malachanne, E. Garcia-Diaz, and M-S. El Youssoufi. Experimental characterization of mechanical properties of the cement-aggregate interface in concrete. Construction and Building Materials, 161:16-25, 2018. 
[33] M. Jebli. Caracterisation a l'echelle locale des proprietes mecaniques de l'interphase pate de ciment-granulat et application a la lixiviation. $\mathrm{PhD}$ thesis, University of Montpellier, 2016.

[34] M. Fremond. Equilibre des structures qui adherent a leur support. Comptes Rendus de l'Academie des Sciences, Paris, 295 (Serie II):913916, 1982.

[35] B. Halphen and Q. S. Nguyen. Plastic and visco-plastic materials with generalized potential. Mechanics Research Communications, 1(1):43-47, Jan 1974.

[36] F. Dubois, M. Jean, M. Renouf, R. Mozul, A. Martin, and M. Bagneris. Lmgc90. In Colloque National en Calcul des Structures. CSMA, 2011. 